\title{
DossIÊ
}

Pedro Fauth Manhães Miranda ${ }^{1}$

Eduardo Tarabauca ${ }^{2}$

\section{A IGREJA CATÓLICA DO SÉCULO XVI SOBRE O INDÍGENA LATINO-AMERICANO: SUJEITO DE DIREITOS?}

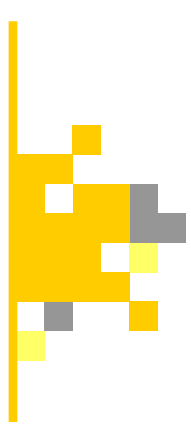

\section{RESUMO:}

Os Estados português e espanhol do séc. XVI eram fervorosamente católicos, de modo que refletiam o caráter histórico da Igreja de então, expressando a catolicidade em seu sentido original, o qual tem como bases a universalidade e o elemento pentecostal daquela crença. Este último traduz-se na necessidade de pregação da palavra católica aos quatro cantos do mundo, promovendo a salvação das almas. Numa conexão, por vezes simbiótica e noutras antagônica, entre tais fatores religiosos e os objetivos imperialistas destas nações, o fato inegável é que surge um fértil desenvolvimento teórico acerca da natureza do ser indígena, questionando-o como sujeito de direitos ou não. Diante disso, o objetivo do presente artigo é demonstrar o debate surgido, no século $\mathrm{XVI}$, a partir de tal conjuntura, por meio de uma revisão bibliográfica dos principais pensadores da época, quais sejam: Antonio de Montesinos, Francisco de Vitória, Bartolomé de Las Casas e Juan Ginés Sepúlveda. Os resultados demonstram que a presente discussão promoveu um desenvolvimento sobre a noção dos direitos naturais, posteriormente retomada quando das revoluções burguesas dos séculos seguintes. Ademais, há uma ressonância óbvia desta contenda sobre a atualidade, transmitindo dos indígenas para os refugiados o questionamento sobre serem ou não sujeitos de direitos. Portanto, apesar de seu surgimento há mais de quatro séculos, a temática em questão possui uma necessidade de ser revisitada, o que se pretende realizar por meio do trabalho a seguir.

Palavras-chave: Colonização Ibérica, Direito Internacional, Igreja Católica, Indígenas, Sujeito de Direitos.

\section{ABSTRACT:}

The Portuguese and Spanish states of the 16th century were fervently Catholic, so they reflected the historical character of the Church at that time, expressing catholicity in its original sense, which is based on the universality and pentecostal element of that belief. The latter is translated into the need to preach the Catholic word to the four corners of the world, promoting the salvation of souls. In a connection, sometimes symbiotic and in other antagonistic, between such religious factors and the imperialist objectives of those nations, the undeniable fact is that there arises a fertile theoretical development about the nature of the indigenous being, questioning it as subject of rights or not. The aim of this article is to demonstrate the debate that emerged in the 16th century from such a context, through a bibliographical review of the main thinkers of the time, namely: Antonio de Montesinos, Francisco de Vitória, Bartolomé de Las Casas and Juan Ginés Sepúlveda. The results demonstrate that this discussion promoted a development on the notion of natural rights, later retaken in the bourgeois revolutions of the following centuries. In addition, there is an obvious resonance of this dispute on the present, transmitting from the natives to the refugees the questioning about whether or not they are subjects of rights. Therefore, despite its appearance more than four centuries ago, the theme in question has a need to be revisited, which is intended to be accomplished through the following work.

KEYWORDS: Iberian Colonization, Internacional Right, Catholic Church, Indians, Subject of Law.

\footnotetext{
${ }^{1}$ Professor de Direito, Sociologia e disciplinas afins nas instituições Sociedade Educativa e Cultural Amélia (SECAL) e Instituto de Filosofia e Teologia Mater Ecclesiae (IFITEME). Doutorando em Direito, pela Pontifícia Universidade Católica do Paraná (PUC-PR). Mestre em Ciências Sociais Aplicadas, pela Universidade Estadual de Ponta Grossa (UEPG). Graduado em Direito e em Ciência Política, respectivamente pela Universidade Estadual de Londrina (UEL) e pelo Centro Universitário Internacional (UNINTER). (iD https://orcid.org/0000-0002-0455-9974

${ }^{2}$ Graduando em Direito pela Universidade Estadual de Ponta Grossa (UEPG) (iD) https://orcid.org/0000-0002-8851-6639
} 


\section{EUROPA, IGREJA E GRANDES NA- VEGAÇÕES}

Em geral, ao se ensinar História, no que tange à atuação de Portugal e Espanha nas Grandes Navegações, se destacam os fatores econômicos que motivaram estas e outras nações a se lançarem ao mar, em busca de novas rotas marítimas capazes de levar as Índias, centro comercial de especiarias. Contudo, há outros fatores importantes que levaram às Grandes Navegações e devem ser considerados.

$\mathrm{Na}$ memória que os estudantes carregam sobre o período, os impulsos religiosos são tratados mais como uma justificativa fingida para as conquistas ultramarinas do que uma experiência cultural verdadeira para os indivíduos do começo do período moderno. De maneira sutil, constrói-se para o aluno a ideia de que, ao findar do período medieval, era uma contradição ter, simultaneamente, metas econômicofinanceiras e impulsos religiosos. (SIQUEIRA, 2009, p.111)

Apesar disso, sabe-se que as navegações que resultaram no "descobrimento" da América tiveram claras influências de alguns setores religiosos, como, por exemplo, a Ordem de Cristo. Isso não significa, por óbvio, afirmar a preponderância destes interesses religiosos, mas uma confluência entre estes e os objetivos econômicos, porém ressaltando a ausência de qualquer relação destes para com os nativos americanos - até porque, até então, ignorava-se a existência dos mesmos.

Deste modo, ainda antes da descoberta do continente americano, a Ordem de Cristo aplicava vultuosos financiamentos nas embarcações que promoviam as Grandes Navegações e demais necessidades destas expedições, a ponto de Portugal mencionar o território brasileiro como propriedade da referida Ordem:

E assim, seis anos antes das viagens de Pedro Álvares Cabral, já Portugal reivindicava a posse da terra do Brasil, para o patrimônio da Ordem de Cristo, segundo as bulas anteriores dos papas $D$. Martinho V, D. Nicolau V e D. Calixto III, porque os descobrimentos portugueses eram custeados pelas rendas da Ordem da Cavalaria de Nosso Senhor Jesus Cristo, isto é, a Ordem de Cristo. (FERREIRA 1980, p.45).

Percebe-se, claramente, uma atuação de cunho imperialista e econômico da Igreja Católica, posto que, neste período, encontrava-se imbricada com os objetivos dos Estados, de modo a haver uma certa confusão entre os poderes destas esferas. Contudo, qualquer que seja o poder (em especial, o de ordem política), sua atuação deve ser legitimada. No caso, a conquista de territórios alémmar encontrava sua legitimação nos interesses econômicos e religiosos da época. Mas e quando tais territórios eram habitados por povos nativos? Seria legítimo sobrepor aqueles interesses sobre tais indivíduos?

Como já afirmado, tal questionamento é impulsionado pela dita "descoberta" das Américas. Neste momento, importa observar que, por duas vezes, foram utilizados substantivos do verbo descobrir, sempre entre aspas - e não por coincidência. Reconhece-se tratar de um termo pouco pacífico entre os historiadores. Se, por um lado, ele é, usualmente, tomado como sinônimo de "achamento" de território antes ignorado, há pesquisadores que o consideram eivado de uma perspectiva eurocêntrica e, por isso, o substituem pela palavra "conquista", evidenciando o subjugo de um povo sobre o outro.

Não obstante o reconhecimento da crítica exposta, esta pesquisa continuará a utilizar-se do termo presente no corpo textual, sendo necessário explanar tal escolha:

Outro importante autor que utiliza a expressão descoberta da América é Tzvetan Todorov. Mas ele a emprega em um sentido inovador: o da descoberta do Outro, do choque que é entrar em contato com uma cultura totalmente diferente. Para Todorov, a descoberta e a conquista da América representaram 
a descoberta dos americanos pelos europeus e vice-versa. E nesse contexto, o mais importante para o estudioso é observar as reações em face da descoberta de culturas diferentes. Para ele, somos todos descendentes de Colombo, ou seja, nossa identidade atual se formou a partir da descoberta da América, quando o mundo se "globalizou" pela primeira vez. (SILVA, 2009, p. 94)

Considerando ser o foco do trabalho as consequências jurídicas deste "descobrimento" do outro, em especial do indígena pelo europeu, entende-se ser a perspectiva de Todorov a que mais se adéqua ao objetivo proposto, pelo que permanecerá neste trabalho, ainda que não traduzindo o aspecto de encontrar o território além-mar.

\section{INDÍGENA: SUJEITO DE DIREITOS?}

O principal nicho intelectual de onde surgiram os mais relevantes teóricos a respeito do tema foi a Escola de Salamanca. Localizada na fronteira entre Espanha e Portugal, a universidade tinha como docentes as seguintes figuras históricas: Francisco de Vitória, Bartolomé de Las Casas, Antonio de Montesinos, Luis de Molina e Domingos de Soto.

A essência das teses defendidas por estes pensadores - tendo, em grande parte, os indígenas como objeto de estudo - promove uma conexão entre a Fé e a Razão, seguindo e mantendo a proposta da Escolástica, sendo tal movimento chamado até mesmo de "Segunda Escolástica". Seguem análises um pouco mais aprofundadas sobre estas teorias, contrapondo dois pontos de vista diametralmente opostos.

\subsection{O INDÍGENA É UM DE NÓS}

As discussões teológicas e filosóficas acerca dos indígenas, ora justificaram, ora denunciaram a atuação europeia em solo americano. A primeira manifestação de oposição a esses atos surgiu de
Antonio de Montesinos (?-1545), num discurso intitulado "Eu sou a voz que clama no deserto" (1511) onde o monge dominicano denunciava os abusos e massacres espanhóis na Hispanhola ${ }^{3}$ frente aos índios, o que resultou em diversas análises e teses no que se refere a natureza dos indígenas e seus direitos. O historiados Lewis Hanke (1965 apud WOODS, 2014, p.129) afirma que o sermão teve "por fim chocar e causar terror entre os ouvintes", por meio das seguintes palavras:

[...] estais em pecado mortal, que viveis
e morreis nele, pela crueldade e tirania
com que tratais este povo inocente.
Dizei-me com que direito ou justiça
mantendes estes índios em tão cruel e
horrível servidão? [...] Por acaso não são
homens? Não possuem almas racionais?
Não estais obrigados a amá-los como
vos amais a vós mesmos? (HANKE, 1965
apud WOODS, 2014, p.129)

Posteriormente, Francisco de Vitória (14921546), um dos pais do Direito Internacional, monge com estudos aprofundados sobre o jus gentium, se uniu a Montesinos, ao lado dos clérigos que defendiam os indígenas. Segundo ele, a natureza humana é essencialmente racional e livre, elementos estes caracterizados por serem frutos da imagem e semelhança divina, e é isto que distingue os homens dos animais, já que estes não têm alma e, portanto, não têm liberdade e nem racionalidade. Ambos os elementos estariam, segundo ele, presentes nos indígenas, ainda que (o que será mais bem explicado posteriormente) essa racionalidade não fosse clara para o europeu.

Vitória, defensor do tomismo, entedia que os direitos não podem ser diminuídos sob o pretexto de pecado. Contudo, quando se trata dos povos indígenas, não haveria que se falar em pecado, pois o mesmo pressupõe a fé, e esta era ausente nos índios, já que "crer depende do querer", nas palavras de São Tomás de Aquino, proferidas já no século XIII. Assim, muitos povos resistiam à conversão ao Catolicismo, motivo pelo qual os es-

\footnotetext{
${ }^{3}$ Território atualmente correspondente à Haiti e República Dominicana.

${ }^{4}$ Resumidamente falando, a Soteriologia é o ramo da Teologia que trata da salvação.
} 
panhóis e portugueses se utilizavam de violência para submeter os povos ao seu domínio, método este totalmente contrário aos princípios da fé.

O embasamento teórico de Vitória era formado pelas ideias de dois sujeitos históricos de notável relevância para o Catolicismo: Paulo de Tarso e o já citado São Tomás de Aquino. Do primeiro, Vitória herdou a concepção de salvação universal, donde o Cristo encarnaria neste mundo para a salvação de absolutamente todos os povos, e não somente dos judeus. Algumas passagens bíblicas deixam este entendimento sotereológico ${ }^{4}$ bem claro: "Já não há judeu nem grego, nem escravo nem livre, nem homem nem mulher, pois todos vós sois um em Cristo Jesus" (BÍBLIA, Epístola aos Gálatas, capítulo 3, versículo 28); e "Prevendo a Escritura que Deus justificaria os povos pagãos pela fé, anunciou esta boa nova a Abraão: $E m$ ti todos os povos serão abençoados" (BÍBLIA, Epístola aos Gálatas, capítulo 3, versículo 8). E ainda:

Porque, diante de Deus, não há distinção de pessoas. Todos os que sem a lei pecaram, sem aplicação da lei perecerão; e quantos pecaram sob o regime da lei, pela lei serão julgados. Porque diante de Deus não são justos os que ouvem a lei, mas serão tidos por justos os que praticam a lei. Os pagãos, que não tem a lei, fazendo naturalmente as coisas que são da lei, embora não tenham a lei, a si mesmos servem de lei; eles mostram que o objeto da lei está gravado nos seus corações, dando-lhes testemunho a sua consciência, bem como os seus raciocínios, com os quais se acusam ou se escusam mutuamente (BÍBLIA, Romanos, capítulo 2, versículos 11-15).

Referente à doutrina tomista, Francisco empresta, além de outras concepções, a noção de lei dividida em três vertentes: a lei eterna, a lei natural e a lei humana. Para Aquino (2005), a lei é uma ordem de natureza racional (e prática) que busca o bem comum e é promulgada por alguém responsável pela comunidade. "Portanto, é neces- sário que, dado que a lei se nomeia maximamente segundo a ordenação ao bem comum, qualquer outro preceito sobre uma obra particular não tenha razão de lei a não ser segundo a ordenação ao bem comum. E assim toda lei ordena-se ao bem comum" (AQUINO, 2005, p.524).

Além disso, a lei seria uma direcionadora dos atos humanos, sendo que as ações são orientadas por elementos interiores (vontade e entendimento) e exteriores (graça e lei), mas sempre com a finalidade onipresente do bem comum. Considerando a existência de tais elementos para todos os eres humanos, a ideologia tomista torna-se bastante inclusiva.

\begin{abstract}
A lei natural é considerada, para São Tomás, como uma participação da lei eterna na criatura racional. Se ela é dada pela razão, mensurável pela natureza, a lei natural não é conhecida apenas pelos crentes. Qualquer ser humano, pela sua participação na natureza, dela pode extrair a lei natural. Ela também fala aos pagãos, e é então por meio dessa lei natural que o que não conhece a fé pode agir no sentido de sua salvação. (MASCARO, 2014, p.114)
\end{abstract}

Desta forma, Vitória estabelece seus argumentos se utilizando de fontes historicamente respeitáveis, de modo que a sua fundamentação tinha peso referencial para a época. No mais, ela embasará parte dos próximos debates sobre o indígena ser ou não sujeito de direitos, os quais ficarão mais acirrados com o passar do tempo.

\subsection{NóS E ELES}

Com o desenvolvimento cada vez mais rápido das Grandes Navegações, outros pensadores passam a fazer parte da presente discussão, promovendo visões mais antagônicas. Um dos principais embates desta época denominou-se "controvérsia de Valladolid" (1550-1551), travada entre Juan Ginés Sepúlveda (1489-1573) e Bartolomé de Las Casas (1474-1566). Las Casas já havia demonstrado seu repúdio sobre muitas das ações 
dos colonizadores, em específico sobre o regime das encomiendas, que consistia em uma doação de terras feita a um colonizador que ficava responsável por evangelizar os indígenas da região; contudo, estes eram obrigados a pagar com serviços a sua catequização - serviços estes que tinham caráter escravagista.

Vale apontar que o próprio Bartolomé de Las Casas havia sido encomendeiro em 1502, abandonando as terras em 1514, pois, apesar de tratar os indígenas com dignidade, não pretendia fazer parte deste instituto jurídico.

Dois eram os principais argumentos de Sepúlveda a favor da dominação espanhola sobre os povos indígenas. $O$ primeiro se constituía na alegada inferioridade cultural destes, baseando esta tese nos costumes tidos como bárbaros, como os sacrifícios humanos, que por definição feririam a Lei Natural. O segundo referia-se à ausência de estrutura política, fruto da suposta escassez de racionalidade, que seria típica do homem escravo por natureza, numa retomada da concepção aristotélica de phýseidoúlos (escravo natural).

Aristóteles negava a concepção da escravidão como fruto da força do maior sobre o menor, daquele vencido na guerra por um oponente mais forte. Para ele, era necessário buscar na natureza o elemento que possibilitaria a distinção entre o homem livre e o escravo. Assim, a única forma de escravidão legítima seria aquela em que os elementos legal e natural confluíssem, dando uma base sólida para tal condição; portanto, o fundamento natural sobrepor-se-ia ao legal.

Dentro da filosofia aristotélica, a alma comanda o corpo, assim como a razão comanda o desejo, seguindo uma ordem de superioridade de um sobre outro. Assim esta divisão também se aplicaria ao homem livre e ao escravo, sendo que este último, natural, se subdivide em dois. O primeiro refere-se à submissão do caráter racional sobre o corpóreo. Já a segunda categoria de escravo natural refere-se à superioridade da razão sobre o desejo. Esta espécie de escravo teria certa racionalidade, mas escassa por si só, obrigando o indivíduo a ser cuidado e guiado por outra pessoa, um senhor; caso contrário, seria guiado por seus desejos, o que para os gregos era deplorável.

Segundo o filósofo: "O mesmo ocorre com o homem relativamente aos outros animais, tanto os que se domesticam quanto aos que permanecem selvagens, a pior das duas espécies. Para eles é preferível obedecer ao homem; seu governo éIhes salutar." (ARISTÓTELES, 2006, p.13)

A primeira categoria, de escravo natural, aquela dos indivíduos cujo corpo é mais robusto e, portanto, mais aptos aos trabalhos manuais, não é o foco das discussões de Valladolid. Contudo, a segunda categoria é a que mais causa discordância, isto porque a suposta razão escassa dos indígenas, demonstrada pela ausência de estrutura política aos moldes europeus, justificaria a sua escravidão ${ }^{5}$. A presença ou ausência de alma nos indígenas deve ser entendida nos moldes da discussão aristotélica, já que não se trata da ausência total da alma, mas sim de sua parte deliberativa. Segundo Tosi:

\begin{abstract}
Aristóteles afirma, várias vezes, que o escravo "participa da razão", que "não pode se negar aos escravos a razão" e que todos, inclusive os escravos, "possuem as partes da alma", mas que Ihes falta totalmente a parte deliberativa (tobouletikón), e por isso ele pode somente perceber a razão, isto é, obedecer às ordens, mas não exercitá-la. Além disso, afirma-se que a diferença entre escravo e livre é qualitativa e não quantitativa, o que significa que não se trata de possuir mais ou menos inteligência ou razão, mas de dois tipos totalmente diferentes de razão, porque o escravo é desprovido da parte mais nobre da alma, ou seja, a parte deliberativa. (GIUSEPPE, 2003, p.90).
\end{abstract}

Las Casas contra argumentava que a racionalidade dos indígenas somente era estranha ao homem europeu, logo, isto não constituía exata-

\footnotetext{
${ }^{5} \mathrm{~A}$ discussão sobre a presença ou ausência de estrutura política e poder nas sociedades indígenas, e quais as consequências desta situação para tais agrupamentos, seria tratada séculos depois por Pierre Clastres, em “A Sociedade contra o Estado" (2003).
} 
mente uma inferioridade intelectual, antes, uma diversidade não compreendida pelos espanhóis.

De outro lado, os favoráveis à submissão dos supostamente inferiores apontavam para os sacrifícios humanos realizados por estes, prática que faria dos mesmos um grupo de bárbaros. Diante disso, Las Casas pontuou algo essencial para a fé cristã e, portanto, ibérica: a noção de sacrifício como oferta a Deus, vide Abraão e Isaque, ou até mesmo o Agnus Dei (o Cordeiro de Deus), Jesus que se oferece na cruz para a salvação dos homens. Portanto, não caberia aos cristãos julgar algo que é essencial para a própria fé de outrem. Ademais, considerando que os europeus haviam cometido massacres em larga escala, nada tinha de coerente em levantarem estas questões (CARVALHO, 2005).

Segundo tal concepção, era impossível que a racionalidade existisse somente em uma parcela dos homens e não em outros:

\begin{abstract}
$\mathrm{Na}$ verdade, não são irracionais, mas possuem o uso da razão a seu modo. Isto é evidente, porque organizam as suas ocupações, têm cidades ordenadas, celebram casamentos, têm magistrados, governantes, leis [...]. Também não se enganam em coisas que são evidentes para os outros, o que revela que usam a razão. Nem Deus nem a natureza falham em dotar as espécies daquilo que lhes é necessário. Ora, a razão é uma qualidade específica do homem, e uma potência que não se atualizasse seria vã (LAS CASAS apud WOODS, 2014. p. 136).
\end{abstract}

Las Casas trouxe à tona a indiferença com que Sepúlveda citava o conceito aristotélico de bárbaro, sem distinguir as diversas classes de bárbaros presentes no livro "A Política", quais sejam: escravo, estrangeiro e aqueles cuja língua não fosse o grego. Não somente isto era problemático na argumentação do monge, mas também o fato de que ignorava a noção escolástica de que Aristóteles, apesar de ter argumentado pelo acesso à Lei por meio da racionalidade, não a tinha em plenitude, pois somente em Cristo a Verdade teria sido plenamente revelada. A noção cristã de amor não estaria nos textos aristotélicos, e para os católicos, isto era problemático.

Las Casas, complementando a classificação de Aristóteles e discordando da deturpação do mesmo por Sepúlveda, divide os chamados bárbaros em dois grandes grupos, sendo que o primeiro comporta outros três subgrupos (primeira, segunda e quarta noção), e o segundo comporta somente um subgrupo (terceira noção) (GUTIÉRREZ, 2014). O primeiro grupo contém os bárbaros secundum quid, ou seja, os classificados como bárbaros por uma falácia que comete uma generalização equivocada, quando na realidade são a exceção. São eles: na primeira noção, os homens bárbaros por serem rudes e cruéis, longes da racionalidade que freia a ira; na segunda, os homens sem escrita; e na quarta e última noção, os homens que não conheciam a Cristo. No segundo grande grupo, há somente os homens escravos por natureza, aqueles que nasceram com maior força bruta que cognição e, por isso, deveriam ser guiados pelos sábios, sendo que os inseridos nestes grupos seriam os escravos de fato.

Os índios não eram bárbaros na primeira concepção, porque não se mostravam cruéis e maldosos, nem na terceira concepção (a legítima em Aristóteles), já que não eram brutamontes sem organização social. Contudo, se encaixavam na segunda e quarta concepção, isto porque não tinham escrita e não conheciam a Cristo. E, assim, esta noção não justificava a sua subjugação.

Na segunda, estavam os que não tinham um idioma literário, ou seja, careciam de escritura. Eram os que não tinham letras nem erudição, e os que, pelo fato de ter outro idioma, não entendiam o que um outro falava. Esses bárbaros não eram propriamente, mas acidentalmente, bárbaros, pois, embora não tivessem escritura, podiam ser sábios, cordatos, prudentes e civilizados. Aristóteles referiu-se a eles no livro 3 da Política (GUTIERREZ, 2014, p.230). 
A quarta classe de bárbaro, acrescentada por Las Casas, também não justificava a dominação sobre os indígenas, pois não era culpa deles ignorarem a Cristo. E, possivelmente, poderiam eles seguir a Lei Natural por meio da razão e se aproximar da Lei de Cristo mesmo sem conhecê-la, como descrito por Paulo de Tarso na Carta aos Romanos.

A discussão ora apresentada, sobre a natureza dos indígenas entre Sepúlveda e Bartolomé de Las Casas, visava à legitimação ou não da guerra justa. O conceito de guerra justa surge no Ocidente com os romanos, em específico com Cícero (106 -43 A.C.), e posteriormente se desenvolve no Cristianismo com Ambrósio de Milão (340-397 D.C.), Agostinho de Hipona (354-430 D.C.) e Tomás de Aquino (1225-1274 D.C.). A guerra justa consiste no preenchimento de duas dimensões de elementos (condições e causas). Em primeiro lugar, temse o jus ad bellum, onde se encontram as causas que levam um Estado a declarar guerra a outro, e em segundo lugar tem-se o jus in bellum, que regula o comportamento desses estados em situação de guerra.

Faz-se necessário pontuar que a guerra, nesta tese, é a ultima ratio, sendo que a paz é sempre a finalidade da guerra justa, e somente nos casos em que a mesma foi violada é que se faz necessário fazer guerra para restituí-la, ou seja, ela não deve ter sentido em si mesma. O jus ad bellum pode ser resumido em: causa justa, intenção justa, autoridade legítima e possibilidade razoável de sucesso. Quanto aos dois últimos, não há muito que discorrer, já que a autoridade dos governantes era reconhecida e as táticas, armas e preparo dos soldados europeus eram muito superiores aos dos indígenas, restando, portanto, dois critérios a analisar: a causa e a intenção.

Como dito, a causa da guerra deve sempre ser a busca pela paz e, neste diapasão, nota-se que os indígenas, apesar de suas guerras entre tribos, não declararam guerra aos que chegaram à América, concluindo-se que não haveria causa justa. Já no caso da intenção justa, vale levantar a o conceito de res nullius ("coisa de ninguém"), terra como que desabitada, isto porque os indígenas, sendo vistos a priori como animais, não ocupavam a terra, já que somente aos seres humanos (sujeitos de direitos) é dado o poder de tomar posse. Assim, sendo a intenção dos europeus o aumento de seus territórios, ela seria justa caso os indígenas não fossem humanos e, portanto, sem o direito de governar o território onde nasceram.

Diante do exposto, segundo Las Casas, não seria necessário tratar do jus in bello, haja visto que naquele contexto, nem mesmo os requisitos do jus ad bellum haviam sido preenchidos.

Interessante observar que, no que tange a estrutura política, retomando a noção de diversidade tida por Las Casas, Domingos de Soto (14941560) e Luis de Molina (1535-1600) defendiam que os indígenas tinham aquilo que posteriormente se tornou um princípio do Direito Internacional: o direito de autodeterminação dos povos. O fato de que os indígenas não tinham uma organização social e política semelhantes à dos povos europeus, não permite que se conclua que eles não tenham o direito de se organizar politicamente à sua maneira, noção que, posteriormente associada à Paz de Westfália (1648), irá fazer surgir o conceito de soberania, fundamentando o dito ramo internacional jurídico.

\section{CONSIDERAÇÕES FINAIS.}

Conclui-se que os diversos encontros entre os povos ibéricos e indígenas geraram um estranhamento, que por sua vez gerou questionamentos a respeito das mais diversas temáticas, tendo em foco a presença ou ausência da alma deliberativa nos povos indígenas e a justificação ou não da dominação europeia por meio de guerra justa.

Esta discussão consagrou os alicerces dos princípios constitucionais liberais e do direito internacional antes mesmo da Revolução Francesa, e joga uma luz sobre aquele período histórico, de modo a demonstrar a evolução do próprio Direito. Interessante observar a influência da doutrina católica na construção de conceitos até hoje largamente debatidos, como o direito de liberdade, in- 
clusive religiosa, e a autodeterminação dos povos.

Porém, ainda que os argumentos próliberdade indígena tenham tido bastante repercussão, inclusive gerando baixa escravização destes (ainda que outros fatores também devam ser considerados), o mesmo não ocorreu com outros povos, notadamente os africanos. Durante muito tempo - e em grande parte do mundo -, os africanos não foram sequer considerados humanos e, portanto, não eram juridicamente classificados como sujeitos de direitos.

Poder-se-ia argumentar que as teorias ora expostas, de Antonio de Montesinos, Francisco de Vitória, Bartolomé de Las Casas e Juan Ginés Sepúlveda, encontram-se datadas, haja visto que, a partir de 1789, todos os seres humanos - sejam eles brancos, indígenas, de descendência africana, ou mesmo de qualquer outra etnia ou credo - são sujeitos de direitos, segundo a Declaração Universal dos Direitos do Homem e do Cidadão, posteriormente substituída, em 1948, pela Declaração dos Direitos Humanos.

Ainda que tal fato seja verdade, também é preciso reconhecer que a efetividade destes direitos está longe de ser alcançada. Mesmo tendo uma natureza de direitos naturais (que foi bastante desenvolvida no período ora retratado), os direitos humanos dos imigrantes e refugiados políticos encontram-se em questionamento por diversos países, e muitos de seus cidadãos utilizam de argumentos estranhamente similares aos do século XVI, seja pela ainda influente ideologia católica ou mesmo por preconceitos quase medievos. É, enfim, a inversão do debate ora analisado, não mais sobre aqueles que aqui estavam, mas sobre os que aqui chegam.

Portanto, apesar de seu surgimento há mais de quatro séculos, é fundamental retomar a temática em questão, seja para melhor conhecer a História dos primórdios do Direito, ou mesmo para transformá-la daqui para diante.

\section{REFERÊNCIAS}

AQUINO, Tomás. Suma Teológica. Vol.4. São Paulo, Loyola, 2005.

ARISTÓTELES. Política. 3.ed. São Paulo: Martins Fontes, 2003.

BÍBLIA SAGRADA. Bíblia sagrada. Edição pastoral. Paulus Editora, 2017.

CARVALHO, Lucas Borges de. Direito e Barbárie na conquista da América Indígena. Revista da Faculdade de Direito UFPR, Curitiba, PR, Brasil, dez. 2005. ISSN 2236-7284. Disponível em: <https:// revistas.ufpr.br/direito/article/view/7024>. Acesso em: 22 out. 2018. doi:http://dx.doi.org/10.5380/ rfdufpr.v43i0.7024.

CLASTRES, Pierre. A sociedade contra o Estado: pesquisas de antropologia política. São Paulo: Cosac \& Naify, 2003.

FERREIRA, Tito Lívio. A Ordem de Cristo e o Brasil. São Paulo: IBRASA - Instituição Brasileira de Difusão Cultural S.A, 1980.

GIUSEPPE, Tosi. Aristóteles e a escravidão natural. Boletim do CPA, Campinas, no 15, jan./jun. 2003. p.71-100 Disponível em: <http://www.puc-rio.br/ parcerias/sbp/pdf/11-giuseppe.pdf $>$. Acesso em 20 de fevereiro de 2019.

GUTIÉRREZ, Jorge Luis. As Controvérsias de Valladolid (1550): Aristóteles, os índios e a guerra justa. São Paulo. Revista USP, N. 101, Março/Abril/Maio. 2014. p.223-235.

MACARO, Alysson Leandro. Filosofia do Direito. São Paulo: Atlas, 2014.

SIQUEIRA, Lúcia. O nascimento da América portuguesa no contexto imperial lusitano. Considerações teóricas a partir das diferenças entre a historiografia recente e o ensino de História. História, São Paulo, 28 (1): 2009.

WOODS, Thomas E. Como a Igreja Católica construiu a Civilização ocidental. 8.ed. Quadrante: São Paulo, 2014. 